\title{
CRÔNICA DE UM FIM ANUNCIADO: O DEBATE ENTRE FREUD E JUNG SOBRE A TEORIA DA LIBIDO ${ }^{1}$
}

Kátia Mariás Pinto

Mestre em psicologia pelo Programa de Mestrado em Psicologia: Estudos Psicanalíticos (Fafich/UFMG); correspondente da Escola Brasileira de Psicanálise, em Minas Gerais.
RESUMO: Este artigo enfoca o histórico da parceria de Freud e Jung no trabalho com psicóticos, e as divergências anunciadas desde as primeiras correspondências trocadas por eles sobre o papel da sexualidade na vida psíquica do indivíduo. O debate com Fliess sobre a sexualidade se constitui como o pano de fundo para todo o desenvolvimento da parceria com Jung. A hipótese central deste artigo é a de que o conceito de libido foi, certamente, um ponto crucial que definiu os rumos da psicanálise em relação à sua concepção do mecanismo causal das psicoses.

Palavras-chave: Freud e Jung, teoria da libido, psicose.

ABSTRACT: Chronicle of an announced end: the debate between Freud and Jung on the theory of the libido. This article focuses on the historical partnership between Freud and Jung in their work with psychotics, and the outlined differences from their very first mail exchanged about the role of sexuality in individual's psychic life. The debate with Fliess about sexuality is the background for the whole development of the partnership with Jung. The main hypothesis of this article is that the concept of libido was, definitely, a crucial point that had defined the way of psychoanalysis towards its conception of the casual mechanism of psychosis.

Keywords: Freud and Jung, libido theory, psychosis.

\footnotetext{
${ }^{1} \mathrm{O}$ título deste artigo faz alusão ao romance Crônica de uma morte anunciada, de Gabriel García Márquez, em que o escritor monta um quebra-cabeça cujas peças vão se encaixando pouco a pouco, revelando, assim, o motivo da morte de Santiago Nasar, anunciada já nas primeiras linhas da narrativa. De modo análogo, esse texto percorre o caminho teórico que levou ao rompimento entre Freud e Jung, anunciado desde as primeiras correspondências devido à incompatibilidade conceitual já então evidente.
} 


\section{O ENCONTRO ENTRE FREUD E JUNG: O FIM ANUNCIADO}

A interlocução entre Sigmund Freud e Carl Gustav Jung iniciou-se em 1906, quando Jung enviou a Freud seus Estudos sobre associações, como resultado de suas experiências com associações verbais. O envio desse livro a Freud marcou o início de uma estreita colaboração, levando-os a manterem uma correspondência e um trabalho intensos por aproximadamente sete anos.

Ao receber o estudo Psicologia da demência precoce, de Jung, Freud revela, numa carta, estar inteiramente de acordo ou apenas aceita sem discussão suas explicações, uma vez que sua experiência com a psicose é pequena. Observa ainda a inclinação do suíço em recorrer às toxinas, omitindo o fator sexual presente nas afecções. Freud, ao contrário, se serve da sexualidade, embora até aquele momento não tenha chegado a uma conclusão.

Percebe-se, desde as primeiras cartas, uma incompatibilidade teórica que fica cada vez mais evidente no decurso do trabalho empreendido por eles. Contudo, é importante ressaltar que Freud interessou-se pela experiência dos psiquiatras suíços $^{2}$ vendo nessa associação uma oportunidade de ampliar os limites das psicoses, além de "cortar o cordão umbilical judaico da psicanálise e torná-la aceitável aos não-judeus” (ZIZEK, 2002, p.14-15), uma vez que Bleuler e Jung não eram judeus. Freud preocupava-se com o fato de que a psicanálise pudesse ser identificada como uma "ciência judaica”. Sua pretensão era de que ela fosse reconhecida como uma ciência com a dimensão universal que estava presente em qualquer discurso científico. Era crucial para Freud a abertura do movimento psicanalítico para outros territórios, para desviar a psicanálise dos intensos preconceitos anti-semitas então existentes. A possibilidade de aplicar a psicanálise à clínica das psicoses deixou Freud entusiasmado com tal parceria.

Nesse momento inicial das correspondências, as diferenças em suas concepções do papel desempenhado pela sexualidade na vida psíquica do sujeito já estão delimitadas. No âmago da problemática da sexualidade, está a teorização da libido, que, como o próprio Freud aponta em sua "História do movimento psicanalítico” (FREUD, 1914a/1990), Jung não levava em conta, mas também não a excluía; porém, em 1912, a propósito da publicação do seu livro Símbolos da transformação: análise dos prelúdios de uma esquizofrenia (1911/1989), atribuiu demasiada importância a este material.

\footnotetext{
${ }^{2}$ Além de Jung, Paul Eugen Bleuler (1857-1939) interessava muito a Freud. Bleuler foi professor de psiquiatria na Universidade de Zurique, diretor do Hospital Burgholzli de 1898 até 1927 e um dos grandes pioneiros da psiquiatria. Ele reviu todo o conceito de demência precoce, passando a chamá-la de esquizofrenia. Bleuler tentava proporcionar à psiquiatria uma base psicológica, não se contentando com a simples descrição dos sintomas das doenças mentais. Ele e seus colaboradores (entre os quais, Jung), faziam experiências de associação verbal, que lhes permitiram descobrir que o distúrbio comum às diversas formas da então chamada demência precoce é a dissociação psíquica, o que o levou a propor o termo esquizofrenia.
} 
A hipótese central de nosso artigo é a de que o conceito de libido foi, certamente, um ponto crucial que definiu os rumos da psicanálise em relação à sua concepção do mecanismo causal das psicoses. Essa pesquisa buscou, no encontro entre Freud e Jung ou, mais especificamente, na controvérsia estabelecida sobre a teoria da libido, a nova etapa da psicanálise. A partir deste ponto, Freud pôde reorientar sua primeira teoria do dualismo pulsional, referindo-se ao auto-erotismo e introduzindo o eu como uma instância de investimento libidinal e não mais apenas os objetos da pulsão. Ficou evidente, portanto, que o debate sobre a libido freudiana acarretou conseqüências cruciais para a concepção psicanalítica das psicoses, tanto que Freud reporta em "Sobre o narcisismo: uma introdução", que o conceito de narcisismo oferece uma alternativa à libido não sexual de Jung, presente nesses casos. Nesse mesmo texto, encontra-se a crítica de Freud à concepção monista da libido presente em Jung, o que permitiu a Freud lançar as bases para uma futura dualidade pulsional necessária à sua concepção de que o conflito é estruturante do funcionamento psíquico. Nesse momento da obra de Freud, a bipolaridade é explicada pela existência de duas libidos — libido do eu e libido do objeto — cada uma implicando uma escolha de objeto, segundo o tipo narcísico ou o tipo de ligação. Essa reformulação da teoria psicanalítica se deu imediatamente após a ruptura com Jung. Mais tarde, estabeleceu outras modificações que culminaram numa reelaboração total de sua concepção dualista das pulsões, em que sobressai a pulsão de morte.

A parceria de Freud e Jung já anunciava a discordância desde o seu início. As cartas trocadas revelam que o interesse pela psicose estava colocado tanto do lado de Jung quanto do lado de Freud, bem como a dificuldade do suíço em captar a essência da noção de sexualidade proposta por Freud.

Jung fez numerosas tentativas de neutralizar o papel da sexualidade, acreditando que a comunidade científica não seria capaz de alcançar a abrangência dessa noção. A noção de sexualidade, na teoria freudiana, escapa à noção restrita de genitalidade e a posição de Jung permanecia divergente daquela de Freud no essencial sobre a libido: para ele a libido não poderia ser apenas a energia da pulsão sexual. Ele a eleva a uma proporção tal que ela sofre muitas transformações, alcançando formas espirituais. Esse é, aliás, o tema do seu livro Metamorfose e símbolos da libido, sobre o qual Freud decide-se por cortar definitivamente as relações com Jung, acusando-o de deturpar a teoria psicanalítica e de não ter entendido nada sobre o inconsciente.

Em "Os três ensaios sobre a teoria da sexualidade" (FREUD, 1905/1990), Freud apresenta o que vem a ser o sexual em seus escritos. Nesse trabalho, ele parte do estudo das "perversões" para afirmar que todas as atividades que constituem a vida sexual dos perversos desempenham o mesmo papel que a satisfação sexual normal desempenha em nossas vidas. Lacan oferece uma chave para a 
leitura do texto freudiano: existe na satisfação libidinal um caráter paradoxal. Esse caráter já está presente em suas elaborações nesse período, mas só vai ser formalizada em 1920, com a publicação de "Além do princípio do prazer".

É exatamente esse caráter paradoxal da satisfação libidinal que escapa a Jung. E aqui, Lacan nos ajuda a perceber que a perspectiva de Jung da libido permanece cativa do imaginário. Para ele, a libido permanece num movimento infinito de investir e desinvestir o eu e dos objetos, transformando-se em figuras variadas, próprias da mitologia. Na teoria junguiana, a libido é essencialmente simbólica, daí sua conclusão da existência de um inconsciente coletivo. Como essa libido é uma energia que se transmite às gerações, ela é o inconsciente arquetípico que possui estruturas fixas transmitidas universalmente.

O problema da sexualidade, na teoria freudiana, está colocado inclusive nos casos de psicose. Em "As neuropsicoses de defesa", um texto de 1894, Freud afirma que "é precisamente a vida sexual que traz as oportunidades para o surgimento de representações intoleráveis" (FREUD, 1894a/1990, p.59) e "o eu rejeita a representação intolerável através de uma fuga para a psicose” (FREUD, 1894a/1990, p.63).

Haveria para Freud, nesse momento, um tipo específico de "recalque" que ele chama de "projeção": uma idéia originada no íntimo é projetada para fora, reaparecendo como se viesse do exterior, como uma realidade percebida. Dessa maneira, o recalque manifesta-se em oposição a tal idéia. O afeto correspondente é retido no eu, ocorrendo a inversão em desprazer. Temos, nesse caso, a paranóia, quando, na tentativa de reencontrar o objeto, a libido transforma as representações em alucinações, com inversão do afeto em desprazer. A libido recalcada é, gradativamente, transformada em convicção, em crença, dando ao delírio toda a sua força.

\section{FREUD E FLIESS: UM RETORNO AO PROBLEMA DA TOXINA}

A interlocução entre Freud e Fliess desperta uma hipótese quanto à tolerância de Freud às idéias de Jung, sobretudo à tendência deste último em recorrer às toxinas, excluindo a sexualidade. Jung justifica o recurso às "toxinas" por temer mal-entendidos provenientes da "notória índole obtusa do respeitável público" - leia-se: comunidade científica. Para ele, a idéia de que uma secreção endócrina "interna" possa ser a causa de perturbações psíquicas e de que talvez a produção das toxinas deva-se às glândulas sexuais é perfeitamente compatível. Mas, devido à falta de provas, abandonou essa hipótese, aplicando-a, mais tarde, à epilepsia, na qual, segundo lê, o complexo sexual-religioso ocupa um lugar central (McGUIRE, 1993, p.58). ${ }^{3}$

\footnotetext{
${ }^{3}$ Carta 12 J, 8 de janeiro de 1907, p.58.
} 
Em seu intercâmbio teórico com Fliess, ${ }^{4}$ Freud confrontou-se com a tendência do médico alemão a orientar-se de forma pretensamente científica. Ambos tinham em comum um grande interesse pela sexualidade e esse interesse leva-os à constatação de que a causa das moléstias que tratavam estava aí: tinham como origem a sexualidade. Fliess procurava descrever os fenômenos da fisiologia médica apoiando-se nas descobertas da física, da química e da matemática. Seu interesse era o de descobrir as bases científicas, sobretudo orgânicas, de uma nova síndrome, que ele chamava de neurose nasal reflexa (SANTIAGO, 2001, p.79-80).

Fliess pretendia demonstrar a origem nasal da dismenorréia e, com isso, a tendência à periodicidade de todas as atividades vitais. Com essa teoria, ele constrói uma verdadeira lei universal da natureza, ou seja, ele atinge uma concepção grandiosa de um universo regulado pela menstruação: “tudo o que é periódico é menstrual" (ANDRÉ, 1987, p.35).

“O objeto dessa lei universal, para Fliess, é a toxina sexual, substância e princípio único, tanto da vida quanto da morte. Ele constrói uma teoria da angústia, tomandoa como o resultado do acúmulo de toxina sexual não liberada pela vida normal."

(ANDRÉ, 1987, p.36)

Freud, por sua vez, tenta estabelecer a teoria da neurose de angústia, que consiste em uma acumulação física de excitação, de tensão sexual física. Para ele, a neurose de angústia é uma neurose de represamento: ela surge por transformação, a partir da tensão sexual acumulada. O que interessa a Freud é a excitação endógena, cuja fonte situa-se dentro do corpo do indivíduo, a saber, a fome, a sede, a pulsão sexual. É apenas quando essa tensão endógena ultrapassa determinado limiar que passa a ter significação psíquica. Ou seja: "acima de certo nível, essa tensão sexual física desperta a libido psíquica que induz ao coito. Quando a reação específica deixa de se realizar, a tensão físico-psíquica (afeto sexual) aumenta desmedidamente" (FREUD, 1894b/1990, p.273). Verifica-se que o termo libido é usado aqui pela primeira vez por Freud, o que permite concluir que o que ele chama de "tensão sexual acumulada" é uma outra maneira de nomear a libido. Pode-se perceber que, na origem da psicanálise, a teoria tóxica da libido ocupa um lugar essencial e é exatamente a hipótese substancialista da libido um dos pontos de contato entre a teoria de Freud e a de Fliess, que é também, como se acabou de ver, a concepção de Jung.

\footnotetext{
${ }^{4}$ Wilhelm Fliess era otorrinolaringologista em Berlim. Foi a Viena no outono de 1887 para estudar e assistiu a algumas conferências de Freud sobre neurologia. A partir de então, os dois iniciam uma correspondência que se estende até 1904. Fliess fez pesquisas sobre as relações entre o nariz e os órgãos.
} 
O relacionamento de Freud e Fliess é fortemente abalado após o dramático episódio com Irma (FREUD, 1900/1990). ${ }^{5}$ Freud, então, recua diante de toda assimilação da sexualidade ao princípio único e universal da toxina, e passa a não acreditar mais no princípio único dessa toxina. Para Freud, a libido apresenta um impulso constante manifesto na pulsão sexual e essa concepção da libido é radicalmente incompatível com o caráter periódico da descarga da toxina sexual em Fliess. Ao contrário de Freud, a libido para Fliess comporta, necessariamente, o fluxo periódico da substância sexual, que, no corpo, viaja entre o nariz e o sexo, passando por vários órgãos e, alternadamente, fazendo-os inchar e murchar. Freud concebe a libido como uma constante energética, como energia suscetível de transformações e trocas. Ele está apoiado no ideal do reducionismo cientificista ao recusar tudo o que está além dessa termodinâmica ${ }^{6}$ energética, pois “todo saber previsível sobre o real da libido corre o risco de cair no delírio paranóico” (SANTIAGO, 2001, p.85).

Ao considerar a toxina sexual um elemento da teoria analítica, Freud acreditava que o progresso da ciência poderia, no futuro, elucidá-lo. Ele mantém-se convencido da necessidade de procurar nas manifestações da libido o traço material do princípio da toxina sexual única. Verifica-se a crença de Freud no substrato tóxico da libido num momento importante de reformulação da sua teoria, a propósito das considerações sobre o narcisismo. Ao mesmo tempo que está respondendo às críticas de Jung, Freud adverte-nos de que as idéias provisórias em psicologia um dia se basearão numa subestrutura orgânica. Isso sugere que os responsáveis pela realização das operações da sexualidade sejam as substâncias e os processos químicos. Ele propõe que essa probabilidade seja levada em conta ao substituir as substâncias químicas especiais por forças psíquicas especiais (FREUD, 1914b/1990). É evidente, nessa passagem, a esperança de Freud de encontrar uma base explicativa para os fenômenos psíquicos nas ciências da natureza.

Portanto, devido ao fato de que Fliess também tomava a toxina sexual como substância e princípio único da vida e da morte é que é possível entender a tolerância de Freud para com as idéias de Jung. Podemos aventar que Jung, ao propor a origem toxina das afecções, encontra em Freud um interlocutor ávido pelos avanços que a ciência poderia realizar em relação à origem da libido.

\footnotetext{
5 Ver também os comentários de Santiago (2001, p.85-90) sobre esse episódio.

6 A termodinâmica é uma parte da física que investiga os processos de transformação de energia e o comportamento dos sistemas nesses processos.
} 


\section{O SCHREBER DE FREUD}

O fato de Jung ter insistido em que Freud lesse a autobiografia do presidente Schreber é outro capítulo importante desse relacionamento. Na Psicologia da demência praecox, Jung já se referia ao livro de Schreber, publicado em 1903, e que, no meio psiquiátrico, vinha sendo muito comentado. Entretanto, Freud só se interessou de fato pela leitura e análise dessa autobiografia bem mais tarde (FREUD, 1911/1990). Esse interesse tardio pelo livro de Schreber provavelmente se deve ao fato de que ele ainda não tinha uma elaboração consistente sobre a psicose e o trabalho com o círculo de psiquiatras suíços possibilitou a investigação psicanalítica das psicoses. O que ele fez com as Memórias (SCHREBER, 1995) de Schreber tornou-se tão relevante que é impossível não associarmos Schreber a Freud. Não se pode deixar de assinalar também que o autor, a partir de seus comentários sobre o texto longo e delirante de Schreber, acaba por introduzi-lo, obrigatoriamente, no percurso de todo psicanalista.

Sua análise conclui que há, na paranóia, uma defesa contra o desejo homossexual, e é exatamente a tentativa fracassada de dominar o homossexualismo a causa da moléstia. Para Freud, o que constitui o cerne do conflito paranóico é a fantasia de desejo homossexual. Essa confirmação é deduzida gramaticalmente a partir da gênese das principais formas de delírios paranóicos, que constituiriam uma defesa contra as pulsões homossexuais e produziriam, exaustivamente, maneiras de negar a proposição: Eu (um homem) o amo (um homem) (FREUD, 1911/1990, p.85).

A partir de Schreber, ele descreve o mecanismo de recalque na paranóia, no qual a libido se desliga silenciosamente das pessoas e coisas antes amadas. O que é ruidoso é o processo de cura, que desfaz o trabalho do recalque e traz a libido de volta às pessoas que ela havia abandonado. Retifica, por conseguinte, o mecanismo da projeção, afirmando que "o que foi abolido internamente retorna desde fora" (idem, p.95).

A megalomania aparece aqui como uma característica comum à maioria dos casos de paranóia, pois se constitui num efeito do desligamento da libido objetal e, ao mesmo tempo numa maneira de tratar a paranóia, à medida que investe no próprio eu, supervalorizando-o.

A conclusão de Freud, em sua análise das Memórias, é que os fenômenos paranóicos e esquizofrênicos podem combinar-se em várias proporções, o que o leva a propor o diagnóstico de demência paranóide, para Schreber. Esse diagnóstico é realizado a partir do fato de que, "na produção de fantasias e de alucinações, Schreber apresenta traços parafrênicos, enquanto que, na causa ativadora, no emprego do mecanismo da projeção e no desfecho, exibe um caráter paranóide” (idem, p.103).

Adicionalmente, enuncia as duas teses que seriam as principais, no sentido de que o estabelecimento da teoria da libido das neuroses e das psicoses estaria 
avançando, ou seja, as neuroses surgem, sobretudo, de um conflito entre o eu e a pulsão sexual, e as formas que elas assumem guardam a marca do curso do desenvolvimento seguido pela libido - e pelo eu (idem). Fica explícito que as formas assumidas pelas neuroses e psicoses são distintas e que essa diferença se deve não apenas aos distúrbios do desenvolvimento da libido, mas também aos distúrbios do desenvolvimento do próprio eu. Essa afirmação de Freud já anuncia que o conflito entre a pulsão do eu e a pulsão sexual não explicará mais a etiologia das psiconeuroses.

\section{JUNG E AS METAMORFOSES DA LIBIDO}

Em Símbolos da transformação: análise dos prelúdios de uma esquizofrenia (1911/1989), Jung se propõe a analisar as suscetibilidades às influências sugestivas de uma jovem esquizofrênica. Ele investiga o lugar de Deus e da religião na vida psíquica do homem. Faz uma análise extensiva dos símbolos nos quais a libido é passível de se transformar e propõe aquilo que põe fim, definitivamente, ao seu relacionamento com Freud: a dessexualização da libido. Lançamos mão, mais uma vez, da terminologia lacaniana para dizer que a teoria junguiana da libido é fundamentalmente imaginária e prevalece o caráter analógico da libido. Essa constatação refere-se ao fato de que sua libido, tomada como uma energia neutra, é deslocada, sucessivamente, para formas espirituais, a ponto de transformar-se em Deus. É exatamente por não acompanhar a noção freudiana sobre o caráter paradoxal da pulsão sexual que ele provoca essa extensão da libido e, conseqüentemente, é levado a dessexualizá-la.

Tais considerações nos levaram a concluir que, não havendo um ponto que interrompa as sucessivas metamorfoses da libido, não há na teoria junguiana o mecanismo do recalque, essencial para introduzir o sujeito no universo da cultura. Ele recusa a interdição do incesto, ele recusa a função simbólica do pai. Isso explica sua insistência no movimento regressivo da libido. À medida que, para ele, o pai não possui a função de interditar a mãe e recalcá-la, o sujeito permanece absolutamente submetido ao incessante jogo da (sua) libido, que não conhece limite. Jung recusa também a noção de constância libidinal, proposta por Freud num momento bem inicial da teoria psicanalítica.

Uma outra vertente para se pensar a proposta de Jung em dessexualizar a libido pode ser buscada na noção freudiana de sublimação. O conceito de sublimação foi introduzido por Freud para indicar que, se não há atividade sexual, tampouco há recalque. A sublimação freudiana coloca o paradoxo de que é possível uma satisfação das pulsões sem atividade sexual e sem recalque. Isso leva Jung a pensar que, se a libido pode satisfazer-se sublimatoriamente, não deve ser sexual. Por isso, ele coloca o acento nas metamorfoses da libido, em suas transformações. E como essa libido é capaz de transformar-se de maneira tal que 
se satisfaz sem sexualidade, ela é, portanto, um elemento não sexual no homem (MILLER, 1998, p.321).

\section{O ROMPIMENTO}

Ao voltar de uma série de conferências que realizou nos Estados Unidos, Jung escreve a Freud entusiasmado com as modificações que fez na teoria psicanalítica, particularmente em relação à teoria da libido. Ele acreditava que a sua nova versão da psicanálise havia conquistado a simpatia de muitas pessoas que até então estavam confusas com o problema da sexualidade na neurose (McGUIRE, 1993, p. 521). ${ }^{7}$

Freud agradece, cordialmente, as notícias sobre a situação da psicanálise nos Estados Unidos, mas indica que "a batalha não seria decidida lá” e critica a atitude de Jung em reduzir as resistências com suas modificações teóricas, sendo taxativo ao dizer que ele não deveria vangloriar-se disso. Freud não hesita também em adverti-lo de que, "quanto mais se afasta do que é novo em psicanálise, mais certeza se tem do aplauso e menos resistência se encontra" (idem, p.523). ${ }^{8}$

A primeira carta de Freud a Jung, do ano de 1913, contém a proposta de que abandonassem, por completo, suas relações pessoais. Freud diz, nessa carta, que "um homem deve subordinar os seus sentimentos pessoais aos interesses gerais do seu ramo de empreendimentos" (idem, p.545-546).

As cartas revelam que Freud, apesar de várias tentativas, não conseguiu convencer Jung do equívoco de sua teoria. É visível também o esforço de Freud em separar a teoria da amizade, elogiando por diversas vezes o livro de Jung. Portanto, essa radical tomada de posição de Freud distingue a psicanálise, definitivamente, da teoria mística de Jung.

É verdade que eles, ainda assim, continuam se correspondendo, porém nenhuma referência mais, no sentido da vida pessoal de cada um, é citada. Discutem, basicamente, questões institucionais, publicações e os preparativos para o Congresso de Munique, que seria realizado nos dias 7 e 8 de setembro de 1913.

Jung visitou a Inglaterra no princípio de agosto, com o objetivo de apresentar trabalhos na Sociedade Psicomédica de Londres e no $17^{\circ}$ Congresso Internacional de Medicina. Apresentou suas divergências com a teoria freudiana da neurose, propondo que a teoria freudiana fosse libertada do ponto de vista puramente sexual e, em seu lugar, fosse levado em conta o "ponto de vista energético" (idem, p.558).

Os desdobramentos da "Quarta Reunião Particular” — o Congresso de Munique — foram a reeleição de Jung à presidência da IPA, embora dois quintos dos

\footnotetext{
7 Carta 323 J, 11 de novembro de 1912, p.521.

${ }^{8}$ Carta 324 F, 14 de novembro de 1912, p.523.
} 
presentes lhe tivessem negado apoio, e a renúncia deste como editor do Jahrbuch für psychoanalytische und psychopathologische Forschungen (Anuário de Pesquisas Psicanalíticas e Psicopatológicas). Com a saída de Jung, a editoração passa às mãos de Karl Abraham. O próximo volume aparecerá em meados de 1914 e continuará a ser publicado por mais um ano, mas com outro título: Jahrbuch der Psychoanalyse (Anuário da Psicanálise). Uma conseqüência importante a ser destacada desse período é, sem dúvida, os dois trabalhos de Freud publicados logo no primeiro volume sobre as diferenças entre os seus pontos de vista e os de Jung e Adler. Suas considerações encontram-se muito bem descritas em "A história do movimento psicanalítico” (FREUD, 1914a/1990) e em “Sobre o narcisismo: uma introdução” (FREUD, 1914b/1990).

\section{A LIBIDO E A PSICOSE: A REALIDADE EM QUESTÃO}

O tema da realidade já é anunciado nas primeiras correspondências de Freud e Jung. Apesar de não ficar claro como Jung define e constrói sua noção de realidade, Freud deixa explícito que a condição para que a realidade seja constituída é a de que algo seja subtraído ao sujeito, funcionando como índice de uma realidade externa. É esse vazio subjetivo que organiza e corrige o mundo interno.

Em 1895, Freud elabora um projeto, conhecido como "Projeto para uma psicologia científica” (FREUD, 1895/1990), no qual sua ambição é apresentar uma psicopatologia nos moldes de uma Naturwissenschaft, ou seja, ele constrói um modelo de aparelho psíquico que funciona segundo o modelo do arco reflexo e é constituído por sistemas de neurônios que recebem a quantidade de excitação e a descarregam, tornando-se de novo vazios. Nesse trabalho, Freud demonstra a função primária do aparelho psíquico, que é a tendência a descarregar toda a excitação que o perturba, negando, dessa forma, o seu próprio funcionamento. Mas, como o aparelho deve manter-se funcionando, faz-se necessária a introdução de uma função secundária, expressa no princípio de constância.

Freud apresenta as duas experiências fundamentais capazes de desencadear a constituição da realidade para o sujeito: as experiências de satisfação e de dor. Ambas as experiências são necessidades do organismo e exigem que se realize no meio externo uma "ação específica” para eliminar a excitação. Essa ação só pode ser realizada por um outro que venha a funcionar como força auxiliar do sujeito. É, portanto, a eliminação da tensão decorrente dos estímulos internos que dá lugar à vivência de satisfação. Toda vez que o estado de excitação e a percepção do desprazer reaparecem, a lembrança do objeto de satisfação será reativada em busca da descarga, produzindo, assim, a alucinação. No funcionamento primário, o aparelho não distingue entre o que é percebido e o que é lembrado.

Essas duas experiências fundamentais - a de satisfação e a de dor — deixam um resíduo, que é o afeto, no caso da dor, e o desejo, no caso da satisfação. 
Tratando-se de desejo, há uma atração primária pelo objeto; já quanto ao afeto, há uma repulsa, uma aversão a investir a imagem do objeto hostil, constituindo a defesa primária (recalque). O processo primário do funcionamento psíquico é caracterizado, portanto, pela atração e pela defesa primárias, mecanismos das experiências de satisfação e de dor, respectivamente. Além disso, esse processo primário visa a identidade de percepção: tanto o objeto temido quanto o objeto desejado são apresentados como percebidos e não como lembrados, ou seja, eles são alucinados. Freud supõe a inibição desse processo para que a realidade possa ser representada psiquicamente. Ele impõe, portanto, um outro tipo de funcionamento, buscando não mais a identidade de percepção, mas a distinção entre o que é percebido e o que é apenas lembrado (FREUD, 1895/1990).

Como o princípio de prazer não é capaz de distinguir o objeto real do objeto alucinado, é necessário um princípio de correção que confira ao aparelho psíquico uma eficiência mínima, que será dada pelo princípio de realidade.

O princípio de realidade não diz respeito ao mundo exterior enquanto tal, mas aos signos que o indicam. Ele atua no nível do processo secundário, regulando o que Freud denominou necessidade vital. Para Freud, é necessário que haja uma suspensão da ação, ou seja, uma inibição da descarga por parte do eu para que possa haver uma diferenciação entre percepção e lembrança e, assim, o processo de pensar se instale. Se a inibição não ocorresse, a intensidade do investimento seria semelhante à produzida pelo objeto externo e a distinção entre percepção e lembrança seria impossível.

Freud atribui um elemento comum à percepção e ao desejo, denominando-o das Ding. Essa estrutura constante não pertence, contudo, propriamente a nenhum dos dois, mas é em torno dela que as representações se organizam. Exterior e estranho, das Ding fica fora daquilo que é regulado pelo princípio de prazer. Apesar de permanecer como um índice exterior irrepresentável, podemos "representar" das Ding como um vazio ou um furo, índice da coisa. Ela faz presença embora esteja ausente. É um vazio que não pode ser preenchido por objeto algum. A ação específica trata justamente de reencontrar das Ding, o objeto que está no centro da experiência de satisfação. O que foi guardado na memória como traço, como informação a respeito de das Ding, será representação, regulada pelo princípio de prazer.

No processo primário, trata-se de fazer coincidir a imagem do objeto com sua representação. A realidade está aí justamente para viabilizar a procura do objeto, não mais tentando uma identidade perceptiva e sim uma identidade mental por meio do processo secundário. Lacan ajuda o leitor a captar melhor essa construção de Freud, ao afirmar que a característica fundamental do aparelho psíquico é que ele está feito não para satisfazer a necessidade, mas para aluciná-la. O princípio de realidade, como princípio de correção, não corrige 
o mundo interno em relação ao mundo externo, mas corrige o mundo interno em relação a ele próprio (LACAN, 1959-60/1997).

Nesse ponto reside outro abismo que separa eternamente Freud de Jung: enquanto a originalidade de Freud diz respeito ao reencontro externo traumático com a Coisa, Jung reinscreve o tópico do inconsciente na problemática da jornada espiritual de autodescoberta interior. Jung vai buscar no núcleo mais profundo da personalidade do sujeito o seu verdadeiro self e, em Freud, não é isso que é encontrado, mas sim a "próton-pseudos" — a mentira primordial. ${ }^{9}$

As elaborações de Freud sobre das Ding apresentadas no "Projeto" tornam-se mais claras quando lidas com o auxílio de um outro texto, curto, mas de igual densidade, "A denegação" (FREUD, 1925/1990), publicado trinta anos depois do "Projeto". Nesse trabalho, Freud apresenta as operações primordiais que definem a constituição do sujeito e, conseqüentemente, seu campo de realidade. Ele mantém a hipótese de que "algo" deve ser expulso, deve estar fora, deve ser perdido, para que esta perda seja incluída, seja aceita pelo sujeito e possa ser, enfim, negada. O esforço a ser feito para assimilar essa operação deve dar-se num tempo lógico, mítico e não cronológico.

Esse texto adverte-nos que a antítese entre subjetivo e objetivo não existe desde o início. Essa antítese surge do fato de que o pensamento é capaz de trazer à mente algo que já tinha sido percebido antes, reproduzindo-o sem que $\mathrm{o}$ objeto externo esteja presente. O principal objetivo do teste de realidade não é, portanto, encontrar na percepção real um objeto que corresponda ao representado, mas sim reencontrá-lo. Assim, uma precondição para o estabelecimento do teste de realidade consiste em que os objetos que outrora traziam satisfação real tenham sido perdidos (FREUD, 1895/1990). A condição da prova de realidade é o objeto perdido: ela exige e força a representação a veicular uma falta - a perda do objeto corresponde à abertura do sistema fechado (exclusivamente econômico) e à ascensão ao mundo da significação: é o processo de nascimento do sujeito e da sua realidade. Trata-se de pôr à prova o exterior pelo interior, da constituição da realidade do sujeito na redescoberta do objeto. O objeto é reencontrado numa busca, uma vez que não se encontra jamais o mesmo objeto (LACAN, 1955-56/1992).

O texto "A denegação" (FREUD, 1925/1990) é um orientador nas elaborações de Freud sobre o processo segundo o qual se constitui o dentro e o fora do sujeito, ou melhor, como se constitui o campo em que o sujeito se insere; quais as conseqüências, para o sujeito, do movimento da libido. A operação que viabiliza a estruturação desse campo da realidade é o par, chamado por Freud de

\footnotetext{
${ }^{9}$ A próton pseudos é uma representação enganadora que esconde uma verdade inconsciente cujo sentido só se torna acessível a posteriori. Ver Freud, "Projeto para uma psicologia científica", p.479-482.
} 
Ausstossung-Bejahung, a saber, expulsão-afirmação. A conseqüência psíquica dessa operação é a Verneinung, o mecanismo da denegação, que comporta o símbolo da negação e permite ao sujeito tomar conhecimento de algo que foi recalcado. É pela via do "não" que se pode dizer o "sim", é o certificado de origem. Ao Made in Germany de Freud, propomos o Made in Pai: a inclusão dessa operação no sujeito é o certificado de que houve a transmissão de um Pai.

A psicose se dá exatamente no nível dessa operação, ou seja, a operação expulsão-afirmação não se efetua e o resultado não é a Verneinung, mas a Verwerfung, traduzida por Lacan como foraclusão. Como a necessária operação que dá início ao processo de simbolização e que insere o sujeito na vida, enquanto vivo não ocorre, o sujeito se encontra fora do universo simbólico, largado e à deriva, sem possibilidades de ancorar-se no enquadre que a realidade proporciona.

\section{CONCLUSÃO}

Na origem da psicanálise, acompanhamos a trajetória de Freud, em sua interlocução com Fliess, propondo a produção da libido a partir das excitações somáticas, numa tentativa de explicar a neurose de angústia como uma intoxicação. O intercâmbio entre eles prosseguiu, apoiando-se no interesse comum em produzir um saber sobre a sexualidade. A libido é um dos pontos de contato dos estudos de ambos. Em Fliess, a teoria da libido comporta o fluxo periódico da substância sexual, que se desloca por toda uma série de órgãos no corpo. Para explicar a neurose, Freud acrescenta à tese fliessiana da periodicidade menstrual da descarga sexual, a dimensão do estado tóxico como paradigma da angústia.

Acreditamos que a tolerância inicial de Freud às idéias de Jung se deva exatamente ao seu histórico com Fliess. O suíço se introduz nesta fresta, capturando o ideal de Freud em relação ao progresso da ciência, a saber, a elucidação dos aspectos tóxicos da origem da libido. Jung era um pesquisador, disposto a aplicar a técnica psicanalítica em seus pacientes psicóticos e a divulgá-la no meio científico de Zurique. A teoria junguiana da libido, como vimos, sofre transformações que alcançam a esfera do transcendente visando o renascimento: a libido é essencialmente simbólica.

As conseqüências imediatas do debate entre Freud e Jung levaram o primeiro a retomar uma discussão ainda mais antiga, anterior à discussão com o psiquiatra suíço: a própria constituição da realidade. Ele é levado a dar maior consistência ao que vinha desenvolvendo a partir do "Projeto" sobre o fato de a realidade se configurar em função de pontos de contato com o objeto perdido. A realidade se organiza à medida que o sujeito se depara com sinais da primeira experiência de satisfação. O que o sujeito busca é o reencontro com o objeto outrora perdido, ou seja, com o objeto que lhe foi extraído, com a libido (sexual) que lhe foi subtraída. Mas esse objeto só é reencontrado, no máximo, como saudade. 


\section{REFERÊNCIAS}

ANDRÉ, S. (1991) O que quer uma mulher? Rio de Janeiro: Jorge Zahar.

FREUD, S. (1990) Edição standard das obras psicológicas completas de Sigmund Freud. Rio de janeiro: Imago.

(1894a) “As neuropsicoses de defesa”, v.III, p.51-65.

(1894b). “Rascunho E”, v.I, p.269-276

(1895) “Projeto para uma psicologia científica”, v.I, p.387-529.

(1900) “Interpretação dos sonhos”, v. IV-V, p.17-611.

(1905) “Três ensaios sobre a teoria da sexualidade”, v.VII, p.118-228.

(1911) "Notas psicanalíticas de um relato autobiográfico de um caso de paranóia”, v.XII, p.15-108.

(1914a) “A história do movimento psicanalítico”, v.XIV, p.13-87.

(1914b) “Sobre o narcisismo: uma introdução”, v.XIV, p.89-119.

(1920) “Além do princípio de prazer”, v.XVIII, p.13-85.

(1925) “A negativa”, v. XIX, p.293-300.

JUNG, C. G. (1986-1989) Obras completas de Carl Gustav Jung. Petrópolis: Vozes.

(1907/1986) “A psicologia da demência precoce: um ensaio”, in Psicogênese das doenças mentais, v.III, p. 1-137.

(1911/1989) Símbolos da transformação: análise dos prelúdios de uma esquizofrenia, v.V, 544p.

LACAN, J. (1998) Escritos. Rio de Janeiro: Jorge Zahar.

(1954/1998) “Comentário falado sobre a Verneinung de Freud”, p. 879 902.

(1954/1988) "Resposta ao comentário de Jean Hyppolite sobre a Verneinung de Freud”, p.383-401.

(1955-1956/1992) O Seminário livro 3, As psicoses. Rio de Janeiro: Jorge Zahar.

(1959- 1960/1997) O Seminário livro 7, A ética da psicanálise. Rio de Janeiro: Jorge Zahar.

McGUIRE, W. (1993) A correspondência completa de Sigmund Freud e Carl G. Jung. Rio de Janeiro: Imago.

MASSON, J. (org.) (1887-1904/1993) A correspondência completa de Sigmund Freud para Wilhelm Fliess. Rio de Janeiro: Imago.

MILLER, J.-A. (1998) Signos del goce. Buenos Aires: Paidós.

SANTIAGO, J. (2001) A droga do toxicômano: uma parceria cínica na era da ciência. Rio de Janeiro: Jorge Zahar.

ZIZEK, S. (2002) “Luta de classes na psicanálise”, in Folha de S.Paulo, Caderno Mais!

Kátia Mariás Pinto

kmarias@terra.com.br 